\title{
ИШЕМИЧЕСКИЙ КОЛИТ (клиническое наблюдение)
}

\author{
Ачкасов С.И., Назаров И.В., Майновская О.А., \\ Семёнова И.И., Орлова Л.П., Скридлевский С.Н. \\ ФГБУ «ГНЦК им. А.Н.Рыжих» Минздрава России, г. Москва \\ (директор - д.М.Н., профессор Ю.А.Шелыгин)
}

\begin{abstract}
Ишемический колит (ИК) возникает из-за острого или хронического нарушения кровотока в кишечной стенке. Группу риска ИК составляют пожилые люди с распространённым атеросклеротическим поражением сосудов, а также лица, перенесшие оперативные вмешательства на магистральных сосудах. Клинические проявления варьируют от незначительной примеси крови в стуле до инфаркта кишечной стенки с развитием перфорации и перитонита. Отсутствие патогномоничных симптомов осложняет раннюю диагностику ИК, а недостаток литературньх данных приводит к противоречиям в вопросах лечебной тактики. В этой статье мы описали клинические примеры двух пациентов, находившихся на лечении в ГНЦК. Эти наблюдения относительно редки, вместе с тем, представляют значительный интерес, особенно в свете существующих дискуссий о природе ИК и подходах к его лечению.
\end{abstract}

[Ключевые слова: ишемический колит]

\section{ISCHEMICCOLITIS (case report)}

Achkasov S.I., Nazarov I.V., Mainovskaya O.A., Semenova I.I., Orlova L.P., Skridlevskiy S.N.

State Scientific Center of Coloproctology, Moscow, Russia

Ischemic bowel disease results from an acute or chronic decline of the blood supply to the bowel and may have various clinical presentations, such as intestinal angina, ischemic colitis (IC) or intestinal infarction. Elderly patients with systemic atherosclerosis who are symptomatic for the disease, congestive heart failure and recent aortic or cardiopulmonary bypass surgery are particularly at risk. The clinical evolution and outcome of this disease are difficult to predict because of its polymorphic aspects and the general lack of statistical data. In this paper, we present two cases of patients who were monitored in our clinic. For these patients, we encountered with pivotal changes in the clinical pattern. These evolutions is particularly rare in common clinical practice, and cases are exemplary because it raises discussions about the nature of the condition and therapeutic decisions that should be made at every stage of the disease.

[Key words: ischemic colitis]

Адрес для переписки: Назаров Илья Владимирович, ФГБУ “ГНЦК им. А.Н.Ръжих» Минздрава России, ул. Саляма Адиля, д. 2, Москва, 123423, e-mail: proctolog.nazarov@gmail.com

Ишемический колит (ИК) известен с 1963 г., когда Boley впервые обнаружил воспалительные изменения в толстой кишке, развивающиеся в результате неадекватного кровотока в кишечной стенке [2]. Частота возникновения ИК может достигать 44-х случаев на 100000 населения в год [4], преимущественно у пожилых пациентов с распространённым атеросклеротическим поражением сосудов и сердечной недостаточностью, однако истинная заболеваемость неизвестна из-за сложности в диагностике. Летальность от этого заболевания колеблется, по разным данным, от 4 до 12\% [6,8]. Значимым фактором риска развития ишемии кишечной стенки является перенесённое оперативное вмешательство на аорте и сердце. Кроме того, к ухудшению кровотока в кишечной стенке могут привести различные состояния, сопровождающиеся системной гипотонией со снижением сердечного выброса, а также длительный приём вазоактивных препаратов и гемодиализ. Гораздо реже ИК встречается в молодом возрасте. Группу риска по возникновению ишемии составляют лица, страдающие системными заболеваниями соедини- тельной ткани (системная красная волчанка, ревматоидный артрит, склеродермия, гигантоклеточный артериит). Есть сведения о том, что курение, запоры, приём оральных контрацептивов и бег на длинные дистанции могут повысить риск возникновения ИК у молодых пациентов [5]. Степень тяжести патологических изменений зависит от локализации и распространённости поражения, остроты начала заболевания. Чаще всего ИК поражает левые отделы ободочной кишки (80\%), реже встречается в поперечной ободочной и правых отделах ободочной кишки (10-20\%), крайне редко ишемические изменения локализуются в прямой кишке (менее 3\%) [3].

Важной особенностью ИК является то, что в подавляющем большинстве случаев не удаётся выявить какой-либо определённой причины, приводящей к развитию ишемии в толстой кишке.

Клиническая картина ИК весьма неспецифична. Наиболее распространёнными проявлениями являются абдоминальный болевой синдром, сочетающийся с гематохезией. Боль, как правило, появляется внезапно и не имеет чёткой локали- 
зации, её интенсивность может варьировать от минимальной до значительно выраженной. У большинства пациентов развивается клиническая симптоматика нарушения кишечной проходимости и системной воспалительной реакции [7].

В диагностике ИК могут быть использованы различные методы визуализации: колоноскопия, компьютерная томография, ангиография, магнитнорезонансная томография, ультразвуковое исследование органов брюшной полости. Однако ни один из перечисленных диагностических методов не может с высокой степенью точности установить ишемический характер поражения кишки.

ИК может протекать под "маской" целого ряда заболеваний желудочно-кишечного тракта: дивертикулярной болезни ободочной кишки, острой кишечная непроходимости, острой формы язвенного колита, псевдомембранозного колита и болезни Крона. Отсутствие патогномоничных признаков, чётких дифференциально-диагностических критериев ИК зачастую становятся причиной запоздалого выявления этого заболевания, выбора неверной лечебной тактики и, как следствие, - ухудшения результатов лечения. Проблему поздней диагностики и неадекватного лечения отчасти можно объяснить отсутствием, на наш взгляд, должного внимания, уделяемого данной патологии. Это побудило нас поделиться собственным опытом лечения больных с ИК.

В 2014 году на лечении в ФГБУ «ГНЦК им. А.Н.Рыжих" Минздрава России находилось двое больных - мужчин 56-ти и 40 лет, с тяжелой формой ишемического колита.

Пациент Ц., 40 лет, был госпитализирован в ГНЦК в июне 2014 года, с жалобами на частый жидкий

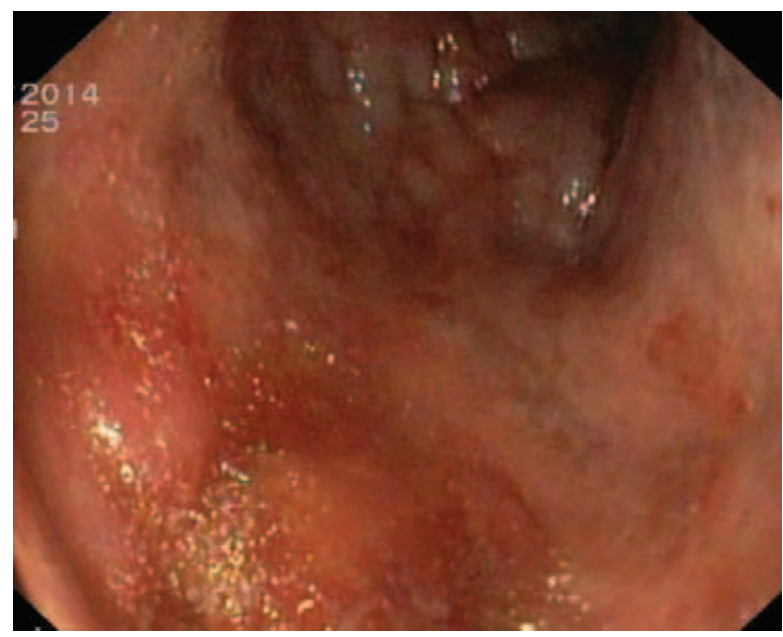

Рисунок 1. Пациент Ц. Колоноскопия. Отёк слизистой оболочки сигмовидной кишки, смазанность сосудистого рисунка стул до 5 раз в сутки, ложные позывы к дефекации до 15 раз в сутки с выделением слизи, боль в левой подвздошной области живота.

Из анамнеза известно, что в апреле 2009 г. больной перенёс левостороннюю гемиколэктомию с формированием трансверзо-сигмоидного анастомоза по поводу рака левого изгиба ободочной кишки T3NoMo. В феврале 2010 г. были выявлены метастазы в IV и VII сегментах печени до 2-х см в диаметре, из-за чего ему выполнена атипичная резекция пораженных сегментов печени. В последующем, было проведено 6 курсов адьювантной химиотерапии в режиме XELOX. В июне 2013 года оперирован по поводу острой спаечной кишечной непроходимости. В апреле 2014 года, на фоне относительного благополучия отметил появление болей в животе и учащение стула, обратился к гастроэнтерологу. При МРТ было выявлено диффузное утолщение стенок сигмовидной и прямой кишок с отеком слизистой оболочки и изменениями окружающей клетчатки воспалительного характера. При УЗИ брюшной полости было заподозрено нарушение венозного оттока от левой половины ободочной кишки. На основании данных обследования, больному был установлен диагноз ИК, назначен низкомолекулярный гепарин, препараты 5-аминосалицилловой кислоты и системная антибактериальная терапия. Несмотря на проведённое лечение, состояние пациента не улучшалось, появилась примесь крови в стуле, из-за чего был назначен преднизолон перорально в дозе 80 мг в сутки и микроклизмы гидрокортизоном в дозе 125 мг. В течении последующих 2-х недель боли усилились, потребовался приём наркотических анальгетиков. Пациент обратился в ГНЦК.

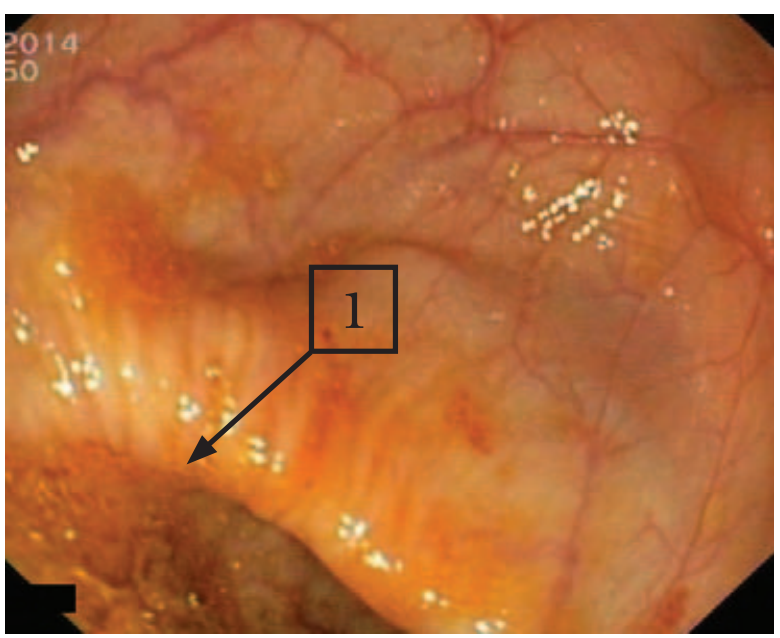

Рисунок 2. Пациент Ц. Колоноскопия. 1 - область трансверзо-сигмоидного анастомоза, проксимальнее которого воспалительные изменения отсутствуют 
При поступлении его состояние расценено как средней тяжести. Кожные покровы и видимые слизистые бледные. Дыхательных и гемодинамических нарушений не выявлено. При пальпации отмечалась болезненность в левой подвздошной области, где ободочная кишка определялась в виде плотного спазмированного тяжа. Симптомы раздражения брюшины не определялись.

В анализах крови отклонений не обнаружено.

При колоноскопии сразу за анальным каналом слизистая прямой и оставшейся части сигмовидной кишки гиперемирована, отёчна, сосудистый рисунок не определялся (Рис. 1). При инсуфляции складки слизистой оболочки не расправлялись. Имелись мелкоточечные геморрагии, эрозии и язвы, покрытые фибрином, данные изменения распространялись вплоть до области трансверзосигмоидного анастомоза (Рис. 2). Сразу за анастомозом проксимальные отделы ободочной кишки выглядели неизменёнными.

При ультразвуковом исследовании были выявлены признаки воспалительных трансмуральных изменений в левых отделах толстой кишки с наличием глубоких язвенных дефектов. Стенка кишки была утолщена до 12-15 мм, слои не дифференцировались (Рис. 3). При допплерографии патологической васкуляризации выявлено не было.

Патологогистологическое исследование биоптатов слизистой оболочки сигмовидной кишки показало наличие в ней склероза с очаговой плазмоцитарной инфильтрацией и полнокровием капилляров. При ирригоскопии определялся свободно проходимый для контрастного вещества трансверзо-сигмоидный анастомоз. Дистальнее зоны анастомоза

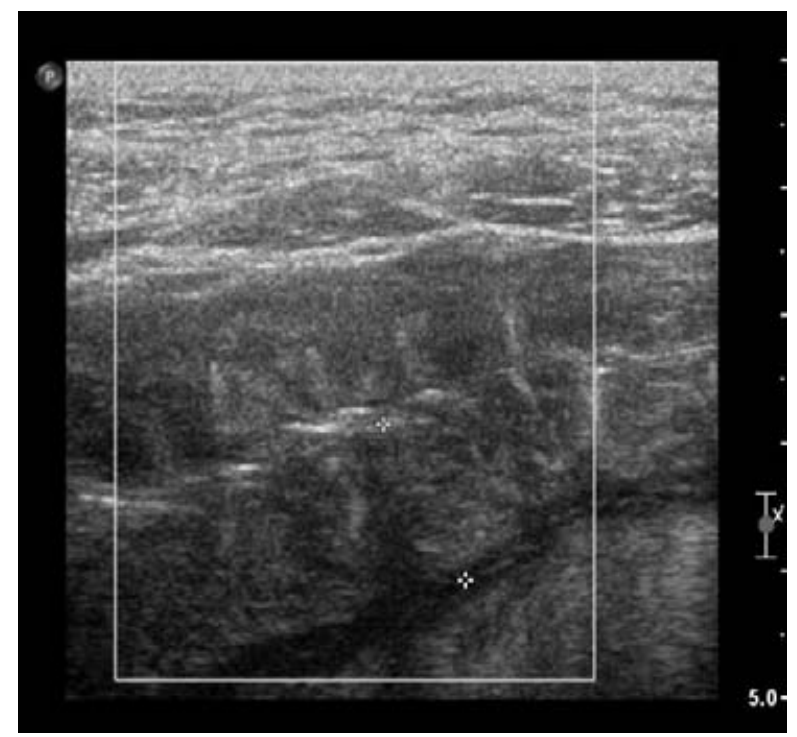

Рисунок 3. Пациент Ц. Ультрасонограмла органов брюшной полости. Утолщение стенок сигмовидной кишки до $15 \mathrm{mм}$ кишка выглядела спазмированной, с утолщенными и деформированными складками слизистой оболочки, ширина просвета не превышала 1,4 см. Проксимальнее анастомоза ободочная кишка выглядела неизменённой (Рис. 4).

Пациенту было выполнено МРТ брюшной полости с внутривенным контрастированием, при котором определялось утолщение стенки сигмовидной кишки до 1,2 см за счет выраженного отека подслизистого слоя. Отмечалось выраженное уплотнение брыжейки сигмовидной кишки, повышенная васкуляризация стенки кишки (Рис. 5).

На основании данных комплексного обследования, пациенту был установлен диагноз "ишемический колит». 11.07.14 пациент был прооперирован. При интраоперационной ревизии стенки сигмовидной кишки дистальнее трансверзо-сигмоидного анастомоза были значительно уплотнены, бледно-розового цвета, местами покрыты фибрином. Брыжейка ободочной кишки утолщена, уплотнена. Регионарные лимфатические узлы увеличены до 0,5 см. Выполнена резекция левых отделов ободочной кишки с брюшно-анальной резекцией прямой кишки с формированием забрюшинной одноствольной трансверзостомы.

При гистологическом исследовании удалённого препарата была выявлена морфологическая картина ишемического колита.

Представленный клинический пример демонстрирует ситуацию, когда диагноз ИК не вызывал сомнений и был установлен ещё до операции. Однако этот пример является лишь исключением из правила. Так, в том же году, на лечении в ГНЦК находился пациент среднего возраста, у которо-

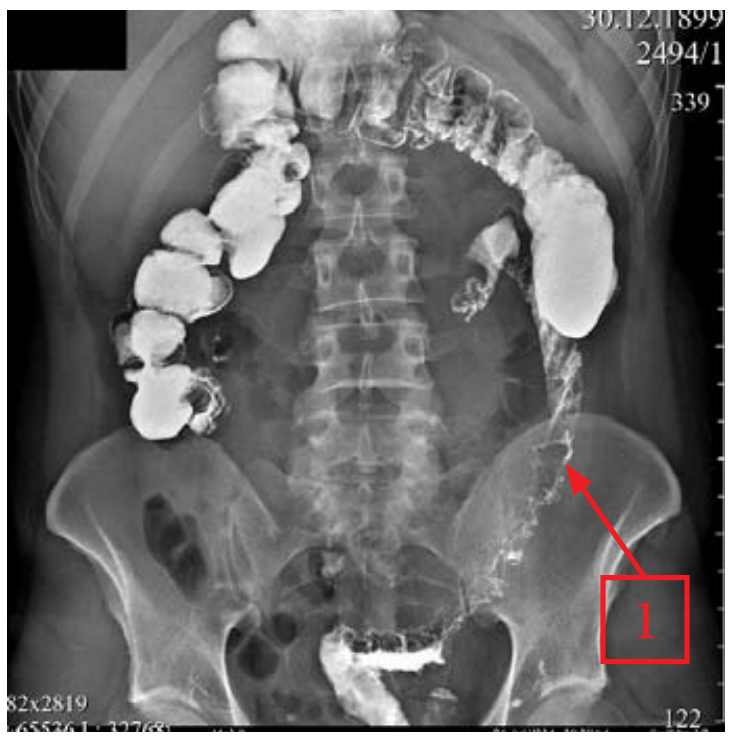

Рисунок 4. Пациент Ц. Ирригограмма в условиях двойного контрастирования. 1 - сужение просвета ободочной кишки дистальнее зоны анастомоза 
го клиническая картина и данные обследования не позволяли однозначно высказаться об ишемической природе заболевания.

Пациент Ш., 56 лет, при поступлении предъявлял жалобы на боли в животе умеренной интенсивности, локализующиеся, преимущественно, в левых отделах, ложные позывы к дефекации, учащение стула с примесью кровянистой слизи, повышение температуры тела до субфебрильных значений, похудание на 15 кг. За полгода до госпитализации, на фоне нарушения диеты и употребления алкоголя отметил появление умеренных болей в животе и частого жидкого стула без патологических примесей. Госпитализирован в стационар по месту жительства, где инфекционная природа заболевания была отвергнута. На фоне проводимой симптоматической терапии состояние пациента улучшилось - боли стихли, частота стула нормализо-

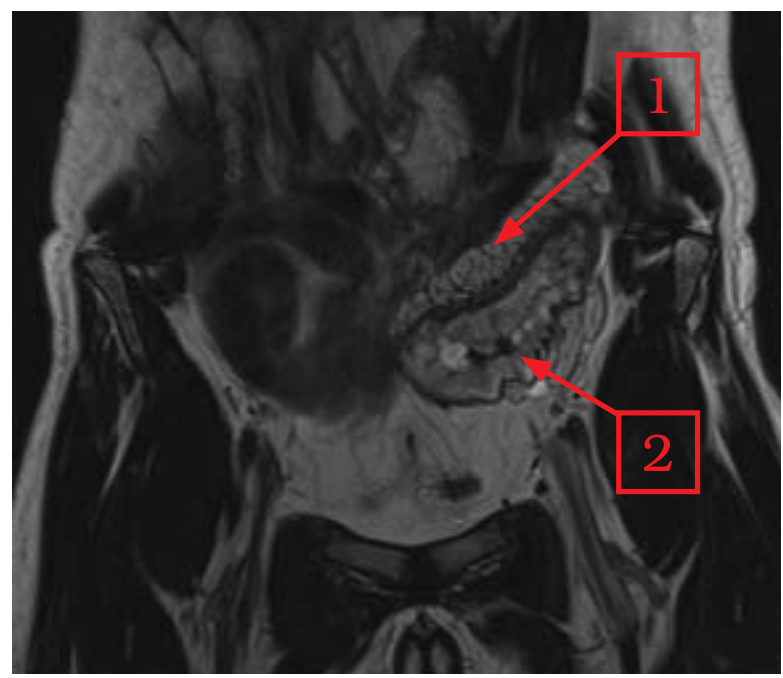

Рисунок 5. Пациент Ц. МРТ брюшной полости с внутривенным контрастированием. 1 - уплотнение брьжейки сигмовидной кишки; 2 - утолщение стенки сигмовидной кишки до 1,2 см за счет отека подслизистого слоя

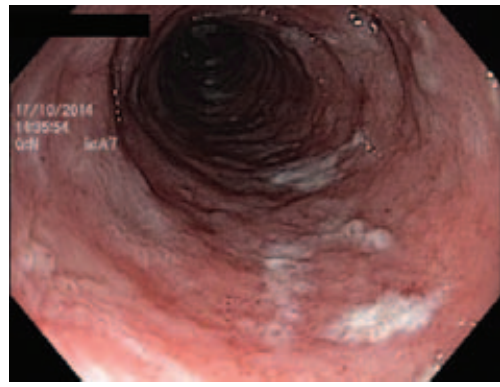

Рисунок 6. Пациент Ш. Колоноскопия. Гиперемия и отёк слизистой оболочки сигмовидной кишки с налётом фоибрина

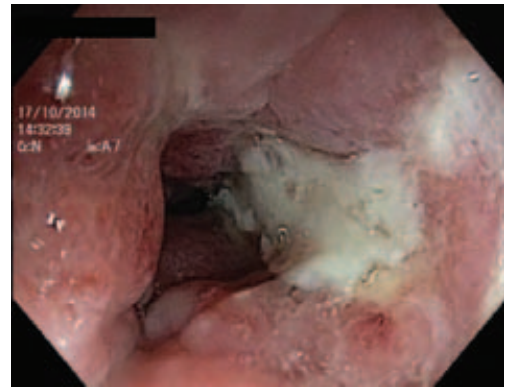

Рисунок 7. Пациент Ш. Колоноскопия. Протяженный язвенный дефбект в нисходящей ободочной кишке, покрытый фибрином валась. При колоноскопии были осмотрены только прямая и сигмовидная кишка из-за возникновения выраженных болей в животе. При этом отмечено сужение просвета осмотренных отделов кишки за счёт отёка и инфильтрации слизистой оболочки кишки. В прямой и сигмовидной кишках по всей окружности определялись множественные сливные язвы звёздчатой формы до 1,5 см в диаметре с наличием фибрина на их дне. Слизистая оболочка вокруг язв выглядела отёчной и гиперемированной с выраженной контактной кровоточивостью. При биопсии пораженной слизистой толстой кишки выявлялись неспецифические воспалительные изменения. Полученные данные были интерпретированы как проявления язвенного колита, из-за чего пациенту была назначена терапия препаратами 5-аминосалицилловой кислоты. Через 3 месяца после начала лечения состояние пациента существенно не изменилось: по-прежнему сохранялся частый жидкий стул до 4 раз в сутки, периодически возникали боли в животе, повышалась температура тела в вечернее время до субфебрильных значений. К концу третьего месяца болезни пациент отметил появление в левых отделах живота опухолевидного, умеренно-болезненного образования, из-за чего обратился в ГНЦК. Важной особенностью анамнеза жизни больного является то, что в 2009 году, он перенёс экстренное оперативное вмешательство в объёме спленэктомии по поводу тупой травмы живота, полученной в дорожно-транспортном происшествии. Какихлибо других заболеваний на момент поступления в ГНЦК у пациента не было.

При осмотре обращала на себя внимание бледность и сухость кожных покровов. Дыхательных и гемодинамических нарушений отмечено не было. При пальпации живота выявлялась болезненность в левой боковой и подвздошной областях, где определялось опухолевидное умеренно-подвижное 
образование в виде "муфты" размерами $6 \times 3 \times 3$ см. При пальцевом ректальном исследовании, начиная от зубчатой линии, слизистая оболочка прямой кишки выглядела отёчной, складки прямой кишки были сглажены. В анализах крови отмечалась анемия лёгкой степени, умеренный лейкоцитоз без нейтрофильного сдвига, повышение уровня С-реактивного белка в 4 раза. В анализах кала избыточного роста патогенной микрофлоры выявлено не было, токсины Cl.difficile также не обнаружены.

Была произведена тотальная колоноскопия, при которой воспалительные изменения выявлялись уже в прямой кишке, просвет её был сужен до 2,5 см в диаметре за счёт отёка слизистой оболочки. Наиболее выраженные изменения определялись в сигмовидной и нисходящей ободочной

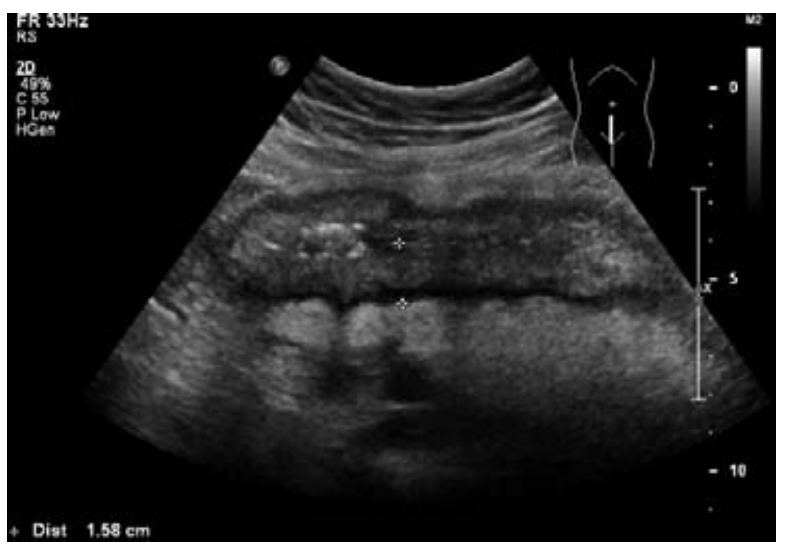

Рисунок 9. Пациент Ш. Ультрасонограмма брюшной полости. Утолщение стенок левьх отделов ободочной кишки до 15 мм

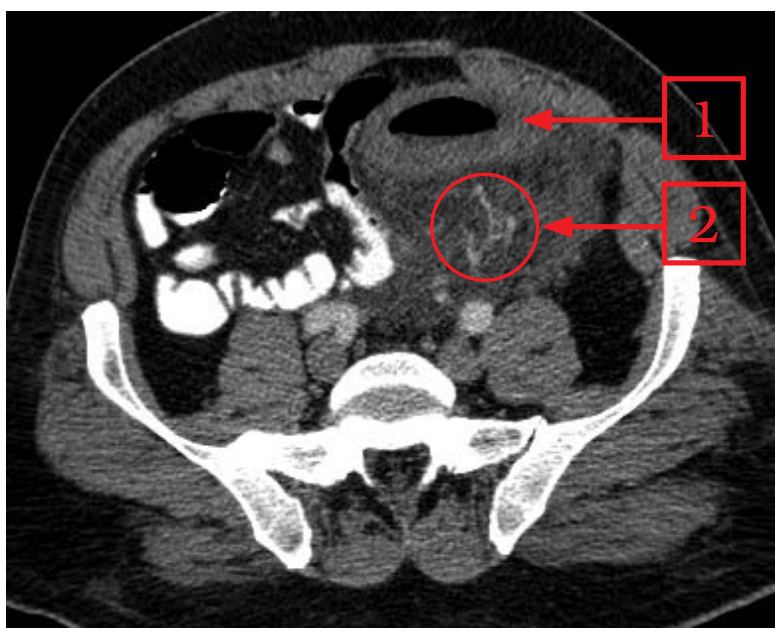

кишках, где прослеживались многочисленные продольные язвенные дефекты, располагавшиеся, преимущественно, по противобрыжеечному краю кишки, протяженность наибольшей язвы составляла 2,5 см. (Рис. 6, 7). Слизистая оболочка левых отделов ободочной кишки выглядела отёчной, со смазанным сосудистым рисунком. Следует отметить, что в слепой, восходящей и поперечной ободочной кишках патологических изменений выявлено не было, а в области левого изгиба имелась чёткая граница перехода от здоровой к воспалительно-изменённой стенке кишки (Рис. 8).

При гистологическом исследовании биоптатов, полученных при колоноскопии, были выявлены склеротические изменения собственной пластинки слизистой оболочки, отмечено снижение числа крипт и бокаловидных клеток в криптах.

При ультразвуковом исследовании левые отделы ободочной кишки выглядели суженными, в виде "трубки" за счет утолщения стенки нисходящей, сигмовидной и верхне-ампулярного отдела прямой кишки до 12-15 мм (Рис. 9), подслизистый слой кишечной стенки левых отделов был отечным, сливался на отдельных участках с мышечным слоем кишечной стенки. В нисходящей кишке определялся глубокий язвенный дефект. При допплерографии в энергетическом режиме в стенке кишки патологическая васкуляризация не определялась. Эхогенность параколической клетчатки была повышена, с наличием узких линейных жидкостных включений длиной до 6 мм. Правые отделы ободочной кишки выглядели неизменёнными.

При компьютерной томографии органов брюшной полости и полости малого таза с внутривен-

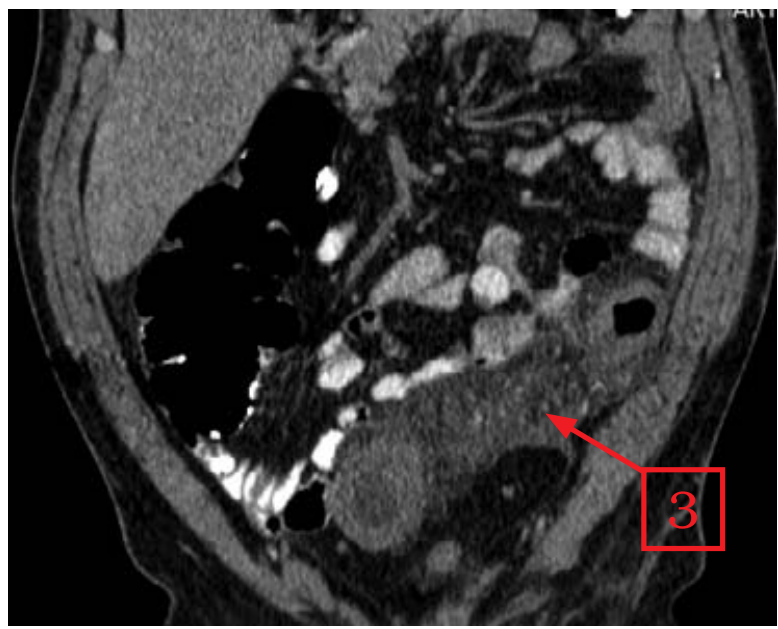

Рисунок 10. Пациент Ш. МСКТ органов брюшной полости и малого таза в условиях внутривенного контрастирования, перорального контрастирования тонкой кишки водорастворимьи контрастньм веществом, ретроградного контрастирования толстой кишки водой.

1 - утолшение стенки сигмовидной кишки;

2 - расширенные сосуды, вследствие застоя крови; 3 - участки жидкостной плотности вследствие транссудации жидкости из сосудов 
ным контрастированием, в условиях перорального контрастирования водорастворимым контрастным веществом и ретроградным контрастированием толстой кишки водой (Рис. 10) выявлено утолщение стенки прямой, сигмовидной и нисходящей кишок до 1,2 см, преимущественно, за счет отека подслизистого слоя. Отмечалась выраженная инфильтрация мезоректальной клетчатки и брыжейки сигмовидной кишки с наличием участков жидкостной плотности, вероятнее всего, вследствие транссудации жидкости из сосудов и застоя крови в сосудах с их расширением. В проксимальном направлении выраженность изменений уменьшалась. Правые отделы ободочной кишки и поперечная ободочная кишка выглядели неизмененными. Парааортально на уровне L2-L4 определялись множественные лимфатические узлы размерами до 1,5 см в диаметре. В тощей и подвздошной кишке патологические изменения обнаружены не были. В магистральных сосудах бассейна верхней и нижней брыжеечных артерий, чревном стволе КТ-признаков тромбоза

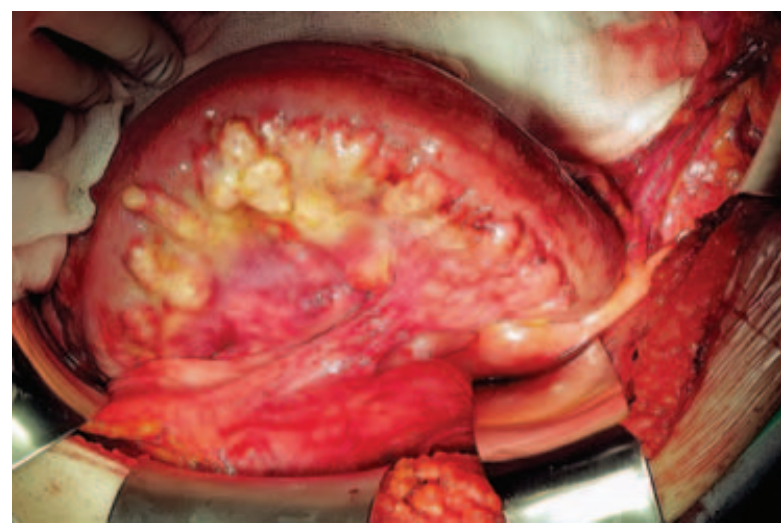

Рисунок 11. Пациент Ш. Интраоперационное фото изменённой сигмовидной кишки

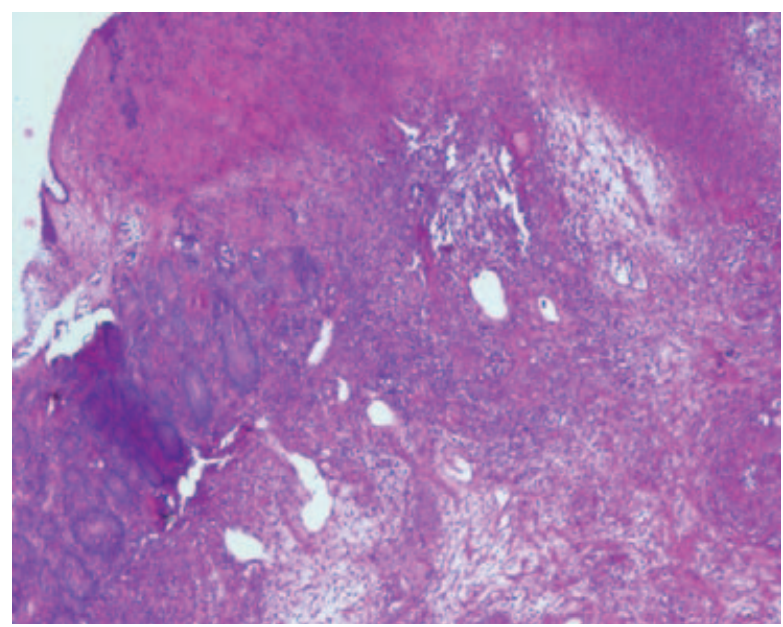

Рисунок 12. Пациент Ш. Изъязвления в сигмовидной кишке с выраженным склерозом подслизистого слоя, склерозом сосудов не установлено. КТ-ангиография не выявила нарушений артериального кровотока. Вместе с тем, было обнаружено замедление венозного возврата в системе нижней брыжеечной вены.

Наличие у пациента воспалительных изменений в левых отделах толстой кишки, осложнённых формированием стойкого сужения ободочной кишки, параколического инфильтрата, нарушением кишечной проходимости и отсутствием эффекта от проводимой консервативной терапии послужило показанием к выполнению оперативного вмешательства. 11.11.2014 г., больной был оперирован. При ревизии выявлено, что правые отделы ободочной кишки и слепая кишка были расширены, содержали оформленный кал и газы. Стенка правых отделов ободочной кишки выглядела нормальной. Основные изменения локализовались в левой половине толстой кишки: сигмовидная, нисходящая ободочная кишка были расширены до 5 см, плотные, с гиперемированной и значительно утолщенной стенкой. Брыжейка левых отделов ободочной кишки также была резко отёчна, утолщена, плотная при пальпации (Рис. 11). Инфильтрация брыжейки сигмовидной кишки распространялась на мезоректальную клетчатку, которая также выглядела значительно утолщенной и уплотнённой. Обращало на себя внимание, что основание нижней брыжеечной вены было вовлечено в рубцовый процесс, развившийся после спленэктомии, который значительно деформировал сосуд, что, вероятно, нарушало отток крови от кишки. Была выполнена операция в объёме левосторонней гемиколэктомии с низкой передней резекцией прямой кишки, илеостомией по Торнболлу. Полость малого таза была дренирована со стороны промежности, тазовая брюшина восстановлена.

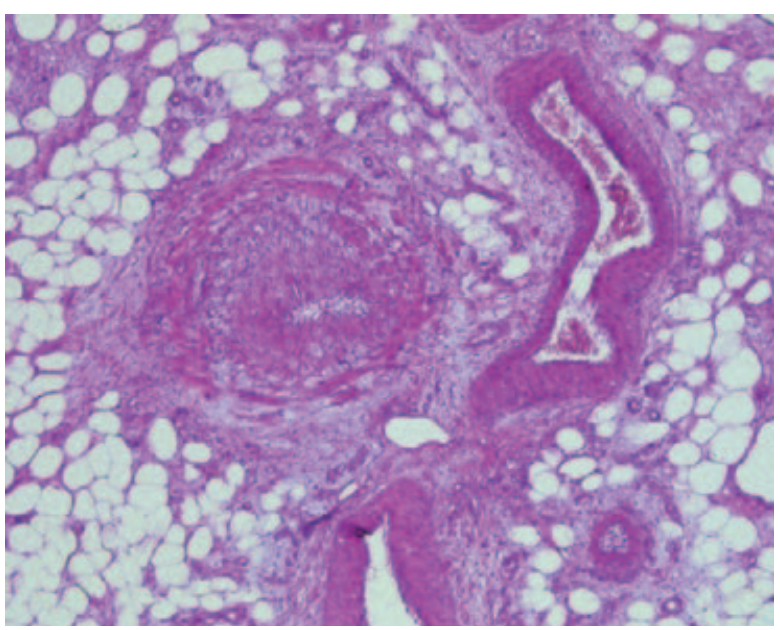

Рисунок 13. Пациент Ш. Выраженный склероз и утолиение стенок сосудов 
При гистологическом исследовании удалённого материала обнаружено утолщение стенки толстой кишки, отёк подслизистой основы и выраженные дистрофические изменения циркулярного мышечного слоя. Во всех слоях кишечной стенки, а также в прилежащей клетчатке выявлялись полнокровные сосуды с резко утолщенными стенками. В сигмовидной и нисходящей кишке локализовались язвы, местами сливающиеся между собой, часть их доходила до середины подслизистой основы, с неравномерно-выраженной воспалительной инфильтрацией (Рис. 12); по периферии язв слизистая оболочка имела выраженный склероз собственной пластинки, а также воспалительную инфильтрацию, распространяющуюся на склерозированную подслизистую основу (Рис. 12). В брыжейке обнаружено множество некрозов с признаками организации, сосуды брыжейки с выраженным склерозом и утолщением стенок. Морфологическая картина соответствовала ишемическому колиту (Рис. 13).

Послеоперационный период пациента Ш. осложнился несостоятельностью швов колоректального анастомоза, по поводу чего проводилась антибактериальная терапия, ежедневные перевязки, промывание дренажей. Через 22 дня после операции пациент был выписан из стационара в удовлетворительном состоянии. Через 3 месяца после операции двуствольная илеостома была ликвидирована. В настоящий момент жалоб не предъявляет, чувствует себя удовлетворительно, работает.

Существующая в настоящее время классификация, основанная на характере патологических изменений, выделяет гангренозный ишемический колит, встречающийся в 15-20\% наблюдений и негангренозный ишемический колит, развивающийся у 80-85\% больных. При отсутствии гангренозно-некротических изменений в кишечной стенке у 60-70\% пациентов ишемия может носить обратимый характер, но в 10-15\% развивается хронический сегментарный колит, который обычно приводит к формированию стриктуры пораженного сегмента кишки.

Наиболее очевидным этиологическим фактором ИК является окклюзия сосудов брыжейки ободочной кишки. Так, до 10\% ишемических колитов возникает из-за нарушения кровотока в системе нижней брыжеечной артерии после протезирования инфраренального отдела аорты или после интервенционных манипуляций под рентгенологическим контролем. Течение окклюзивного варианта ИК, чаще всего, тяжелое, приводящее к развитию гангрены кишечной стенки и требующее срочного хирургического лечения [3]. В случае пациента Ц., перенесшего левостороннюю гемиколэктомию, наиболее вероятной причиной возникновения колита могла явиться хроническая ишемия за счёт недостаточного кровотока из системы средней ободочной артерии. Патогенез ИК у пациента Ш. до конца неясен, нами не были выявлены факторы, предрасполагающие к развитию ишемии, а сохранённый артериальный кровоток в брыжейке и стенке ободочной кишки, выявлявшийся при ультразвуковом исследовании и компьютерной томографии может говорить о неоклюзионной природе ИК. В тоже время, выявленные рубцовые изменения нижней брыжеечной вены могли послужить причиной развития ИК из-за нарушения венозного оттока от кишечной стенки. Описанные случаи наглядно показывают, что ИК следует заподозрить не только у пациентов, имеющих распространённый атеросклероз или перенесших сосудистые операции, но и у всех, у кого были симптомы неустановленной патологии органов брюшной полости.

Представленные клинические примеры демонстрируют сложность дифференциальной диагностики и выбора тактики лечения больных с хронической формой ишемического колита.

\section{ЛИТЕРАТУРА}

1. Agarwal A., Banerjee A., Banerjee U.C. Xanthine oxidoreductase: a journey from purine metabolism to cardiovascular excitation-contraction coupling. Crit. Rev. Biotechnol. - 2011; 31 (3): 264-80.

2. Boley S.J., Schwartz S., Lash J. et al. Reversible vascular occlusion of the colon. Surg. Gynecol. Obstet. - 1963. 116: 53-60.

3. Brandt L.J., Feuerstadt P., Longstreth G.F. et al. ACG clinical guideline: epidemiology, risk factors, patterns of presentation, diagnosis, and management of colon ischemia (CI). Am. J. Gastroenterol. - 2015 110 (1): 18-44.

4. Higgins P.D., Davis K.J., Laine L. Systematic review: the epidemiology of ischemic colitis. Aliment. Pharmacol. Ther. - 2004; 19 (7): 729-38.

5. Kimura T., Shinji A., Horiuchi A. et al. Clinical characteristics of young-onset ischemic colitis. Dig. Dis. Sci. - 2012; 57 (6): 1652-9.

6. Longstreth G.F., Yao J.F. Epidemiology, clinical features, high-risk factors, and outcome of acute large bowel ischemia. Clin. Gastroenterol. Hepatol. - 2009; 7 (10): 1075-80.

7. Reissfelder C., Sweiti H., Antolovic D. et al. Ischemic colitis: who will survive? Surgery. - 2011: 149 (4): 585-92.

8. Yadav S., Dave M., Edakkanambeth Varayil J.et al. A population-based study of incidence, risk factors, clinical spectrum, and outcomes of ischemic colitis. Clin. Gastroenterol. Hepatol. - 2015; 13 (4): 731-8. 